\title{
The utility of biomarkers in diagnosis of aspirin exacerbated respiratory disease
}

\author{
Suzy A. A. Comhair ${ }^{* *}$, Grazyna Bochenek², Sara Baicker-McKee ${ }^{1}$, Zeneng Wang ${ }^{1}$, Tomasz Stachura², Marek Sanak², \\ Jeffrey P. Hammel', Stanley L. Hazen', Serpil C. Erzurum ${ }^{1,3}$ and Ewa Nizankowska-Mogilnicka ${ }^{2}$
}

\begin{abstract}
Background: Aspirin-exacerbated respiratory disease (AERD) is a distinct eosinophilic phenotype of severe asthma with accompanying chronic rhinosinusitis, nasal polyposis, and hypersensitivity to aspirin. Urinary 3-bromotyrosine (uBrTyr) is a noninvasive marker of eosinophil-catalyzed protein oxidation. The lack of in vitro diagnostic test makes the diagnosis of AERD difficult. We aimed to determine uBrTyr levels in patients with AERD $(n=240)$ and aspirintolerant asthma (ATA) $(n=226)$ and to assess whether its addition to urinary leukotriene $E_{4}\left(u_{L T E}\right)$ levels and blood eosinophilia can improve the prediction of AERD diagnosis.
\end{abstract}

Methods: Clinical data, spirometry and blood eosinophilis were evaluated. UBrTyr and $\mathrm{ULTE}_{4}$ levels were measured in urine by HPLC and ELISA, respectively.

Results: Both groups of asthmatics (AERD, $n=240 ; A T A, n=226$ ) had significantly higher uBrTyr, uLTE 4 levels, and blood eosinophils than healthy controls $(\mathrm{HC})(n=71)(p<0.05)$. ULTE 4 levels and blood eosinophils were significantly higher in AERD as compared to ATA ( $p=0.004, p<0.0001$, respectively). whereas uBrTyr levels were not significantly different between both asthma phenotypes $(p=0.34)$. Asthmatics with high levels of uBrTyr $(>0.101 \mathrm{ng} / \mathrm{mg} \mathrm{Cr})$, uLTE levels (> $800 \mathrm{pg} / \mathrm{mg} \mathrm{Cr}$ ) and blood eosinophils (> 300 cells/ul) were 7 times more likely to have AERD.. However, uBrTyr did not increase the benefit for predicting AERD when $\mathrm{ULTE}_{4}$ and blood eosinophils were already taken into account $(p=0.57)$.

Conclusion: UBrTyr levels are elevated both in AERD and ATA as compared to HC, but they could not differentiate between these asthma phenotypes suggesting a similar eosinophilic activation. The addition of uBrTyr to elevated uLTE4 levels and blood eosinophils did not statistically enhance the prediction of AERD diagnosis.

Keywords: Asthma, BromoTyrosine, Leukotriene, AERD

\section{Background}

Around $7 \%$ of asthmatics are hypersensitive to aspirin and other non-steroidal anti-inflammatory drugs (NSAIDs) [1]. This asthma phenotype, referred to as Aspirin-Exacerbated Respiratory Disease (AERD), is characterized by the presence of usually severe asthma, chronic rhinosinusitis with nasal polyposis, and acute asthma attacks with naso-ocular symptoms after ingestion of aspirin and other NSAIDs [2]. Previous studies have shown that patients with AERD have increased emergency department visits, hospitalizations, and corticosteroid bursts compared to

\footnotetext{
*Correspondence: comhais@ccf.org

${ }^{1}$ Cleveland Clinic, Lerner Research Institute, 9500 Euclid Avenue, NB2-40,

Cleveland, $\mathrm{OH}$ 44195, USA

Full list of author information is available at the end of the article
}

those with aspirin-tolerant asthma (ATA) [3, 4]. About half of AERD patients have severe asthma that requires chronic treatment with high dose of inhaled corticosteroids or oral corticosteroids to control the disease $[4,5]$.

AERD is an inflammatory condition of the upper and lower airway characterized by increased eosinophils and mast cells. Mechanistic studies have shown that AERD is linked to abnormalities/dysregulation of the cyclooxygenase (COX) and lipooxygenase (LOX) pathway $[2,6]$. It has been suggested that abnormal regulation of 5-LOX and leukotriene $\mathrm{C}_{4}$ synthase (LTC4S) pathways that results in increased production of cysteinyl leukotrienes (CysLTs) leads to asthmatic attacks [2, 7, 8]. Urinary leukotriene $\mathrm{E}_{4}\left(\mathrm{uLTE}_{4}\right)$, a stable CysLTs metabolite, is used to measure their systemic production [9] and can 
be helpful in differentiating AERD from ATA [10, 11]. Sources of $\mathrm{LTE}_{4}$ include many cells of the upper and lower airways such as eosinophils, mast cells, basophils, as well as macrophages, platelets, and neutrophils [12].

Eosinophils are important effector cells in asthma and even more so in AERD. Blood eosinophilia is well-recognized biomarker of active inflammation in asthma [13, 14]. Activated eosinophils degranulate to release among others eosinophil peroxidase (EPO), which is unique in its ability to convert respiratory burst-generated hydrogen peroxide into hypobromous acid, a reactive brominating oxidant that modifies protein tyrosine residues, forming 3-bromotyrosine (BrTyr) [15, 16]. BrTyr, a biochemical fingerprint of eosinophil activation as a highly stable product can be detected in urine.

Currently, oral aspirin challenge is the gold standard to confirm the diagnosis of AERD $[17,18]$. However, this test is time-consuming, can cause adverse reactions, and is unsuitable in severe asthma patients [17]. Therefore, noninvasive methods that could assist in diagnosis are urgently needed.

To our knowledge, there is no generally recognized, clinically available in vitro test or biomarker to determine the presence of AERD.

The purpose of this study was to determine uBrTyr levels in patients with AERD and ATA and to explore if uBrTyr might predict AERD. Moreover, we wanted to test whether adding elevated uBrTyr levels to elevated $\mathrm{uLTE}_{4}$ levels and blood eosinophil counts could improve the prediction of AERD.

\section{Methods}

\section{Study population}

Patients with asthma were recruited from the outpatient clinic of the Department of Internal Medicine, Jagiellonian University Medical College, Krakow. All patients were clinically stable without any asthma exacerbations within the 6 weeks preceding the study. All data and sample collection have been previously described [11].

The diagnosis of AERD was determined through typical clinical presentation and at least 1 asthma attack after ingestion of aspirin or another NSAID in the past. This diagnosis was confirmed by a positive aspirin challenge in the majority of patients. However, clinical safety limitation prohibited a small group of AERD patients $(16.7 \%, n=40))$ with very severe asthma to undergo aspirin challenge. Their aspirin hypersensitivity was confirmed based on their medical history with previous reactions related to ingestion of NSAIDs well documented in medical records. Removal of these severe asthmatics could introduce additional bias in characteristics of AERD phenotype, for which severe steroid dependent asthma is very typical.
All ATA patients had used aspirin without any adverse effects. Healthy control subjects (HC) without history of asthma, allergy, and any hypersensitivity reactions to NSAIDs were enrolled for comparison of baseline values of inflammatory biomarkers.

Written informed consent was obtained from all participants under a protocol approved by the Jagiellonian University Ethics Review Committee.

Evaluation of asthma was determined by the National Asthma Education and Prevention Program (NAEPP) EPR-3 guidelines [19].

Asthma control was assessed by the Asthma Control Test (ACT) [20].

\section{Study procedures}

Spirometry (MasterScreen, Jaeger, Wurzburg, Germany) was carried out at baseline and after administration of 4 puffs of salbutamol. The best of 3 repeatable forced expiratory maneuvers was recorded. The percent predicted values of $\mathrm{FEV}_{1}$ and $\mathrm{FEV}_{1} / \mathrm{FVC}$ were automatically calculated.

Blood eosinophil counts were calculated using a Fuchs-Rosenthal chamber.

\section{Urine analysis}

Morning urine samples were collected after a $2 \mathrm{~h}$ accumulation of urine in the bladder which allows for less variation in urine creatinine levels [10].

Urine creatinine was measured by enzymatic method using automated chemical analyzer COBAS Integra 400 plus (Roche Diagnostics USA, Indianapolis, IN).

Urinary BrTyr was assayed using stable isotope dilution High Performance Liquid Chromatography (HPLC) with on-line electrospray ionization tandem mass spectrometry. First, a solid phase extraction was performed. Briefly $20 \mu \mathrm{l}$ internal standard composed of $0.5 \mu \mathrm{M}$ synthetic $\left[{ }^{13} \mathrm{C}_{6}\right]$-3-bromotyrosine, $1 \mathrm{mM}\left[{ }^{13} \mathrm{C}_{9},{ }^{15} \mathrm{~N}\right]$ tyrosine, and $1 \mathrm{mM}$ creatinine- $\mathrm{d}_{3}$ (Cambridge Isotope Laboratories) was spiked into $200 \mu \mathrm{l}$ urine followed by acidification with $1 \mathrm{ml} 0.1 \%$ formic acid. The acidified urine was loaded to a Biotage ${ }^{\circ}$ auto solid phase extraction system with $3 \mathrm{ml}$ DSC- 18 column used. DSC-18 column was balanced with $2 \times 3 \mathrm{ml}$ methanol and then $2 \times 3 \mathrm{ml} 0.1 \%$ formic acid, washed with $2 \times 3 \mathrm{ml} 0.1 \%$ formic acid, and the product was eluated with $3 \mathrm{ml} 0.1 \%$ formic acid in 30\% methanol. The product was dried under SpeedVacuum, and then resuspended in $100 \mu \mathrm{l}$ $\mathrm{H}_{2} \mathrm{O}$. Secondly, LC/MS/MS was used to quantify urinary BrTyr. Five microliters of the extraction was analyzed by injection onto a $\operatorname{Titan}^{\text {tw }}$ C18 UHPLC Column $(1.9 \mu \mathrm{m}$ particle size, $\mathrm{L} \times \mathrm{I}$.D. $10 \mathrm{~cm} \times 2.1 \mathrm{~mm}$, Supelco) at a flow rate of $0.4 \mathrm{ml} \mathrm{min}{ }^{-1}$ using a 2 Shimadzu LC-20 AD Nexera CL pump system, SIL-30 AC MP CL autosampler interfaced with an Shimadzu 8050 mass 
spectrometer. A discontinuous gradient was generated to resolve the analytes by mixing solvent A $(0.2 \%$ formic acid in water) with solvent $\mathrm{B}(0.2 \%$ formic acid in methanol) at different ratios starting from $0 \% \mathrm{~B}$ for $3 \mathrm{~min}$, then linearly to $100 \%$ B over $3.5 \mathrm{~min}$, then hold for $3 \mathrm{~min}$, and then back to $0 \% \mathrm{~B}$. $\left[{ }^{13} \mathrm{C}_{9},{ }^{15} \mathrm{~N}_{1}\right]$-tyrosine was included to simultaneously monitor for potential artificial generation of analyte. 3-bromotyrosine, creatinine, and their respective internal standards $\left[{ }^{13} \mathrm{C}_{6}\right]$-3-bromotyrosine and creatinine- $\mathrm{d}_{3}$ were monitored using electrospray ionization in positive-ion mode with multiple reaction monitoring (MRM) of precursor and characteristic product-ion transitions of $m / z 260 \rightarrow 135,114 \rightarrow$ $44,266 \rightarrow 141$ and $117 \rightarrow 47 \mathrm{amu}$, respectively. The parameters for the ion monitoring were optimized automatically. Nitrogen (99.95\% purity) was used as the source, and helium was used as collision gas. Various concentrations of nonisotopically-labeled 3-bromotyrosine were spiked into control urine to prepare the calibration curves for quantification of 3-bromotyrosine. The internal standard $\left[{ }^{13} \mathrm{C}_{6}\right]$-3-bromotyrosine was used for quantification as well as to calculate recovery rate of TMAO (which was $>80 \%$ based on separate control studies). Under the conditions employed for the assay, no artificial bromination was detected. Results of urinary BrTyr were expressed in nanograms per $\mathrm{mg}$ of creatinine.

$\mathrm{ULTE}_{4}$ was measured in unpurified urine samples by direct enzyme immunoassay (Cayman Chemical, Ann Arbor, MI). Supernatants of freshly collected spot urine samples were stored at $-80^{\circ} \mathrm{Celsius}$ for not longer than 6 months. After thawing at $4{ }^{\circ} \mathrm{C}$, urine was diluted in phosphate buffered saline $(1: 10)$. The measurement was repeated using 1:30 dilution of urine for samples in which the $\mathrm{LTE}_{4}$ concentration exceeded the uppermost calibrator concentration of the assay $(1000 \mathrm{pg} / \mathrm{mL})$. Results of urinary $\mathrm{LTE}_{4}$ measurements were expressed in picograms per mg of creatinine.

\section{Statistical analyses}

Quantitative characteristics of the study population were described using mean and standard error, while categorical characteristics were described using means and percents. Groups were compared with respect to baseline quantitative characteristics and marker levels among the groups with t-tests and analyses of variance for approximately normally distributed variables, while the Wilcoxon rank-sum test was used with respect to variables demonstrating non-normal distributions. Groups were compared using the likelihood-ratio $x^{2}$ test with respect to categorical variables. To evaluate uBrTyr, $\mathrm{uLTE}_{4}$, and blood eosinophils as biomarkers for AERD diagnosis, cut-points were used. A receiver operating characteristic (ROC) analysis was used to identify an optimal cut-point for uBrTyr and $\mathrm{uLTE}_{4}$. A cut-point for blood eosinophils $>300$ cells/ $\mu \mathrm{L}$ was based on published data [21, 22]. Logistic regression was used to estimate odds ratios for the identification of AERD (vs ATA) with respect to the dichotomized forms of the biomarkers. The logistic regression analyses were also performed with covariate adjustment for baseline $\mathrm{FEV}_{1} \%$, chronic rhinosinusitis, and any steroid use was performed with the logistic regression modeling. The incremental predictive ability of each marker in the regression model was assessed using areas under the ROC curves estimated with 10-fold cross-validation for the full model and for models excluding markers individually. Correlations among quantitative variables were assessed using Spearman's rank-sum correlation coefficients, which are suitable for data with any distribution. A $p$-value less than or equal to 0.05 was defined as statistically significant.

\section{Results}

\section{Subject characteristics}

The study included 240 patients with AERD, 226 patients with ATA, and $71 \mathrm{HC}$. Almost the same population has been previously described [11]. The clinical characteristics of the study subjects are shown in Table 1. Age and gender were distributed significantly differently in asthmatics, i.e., AERD and ATA when compared to (HC), but no difference between AERD and ATA was found. (Table 1). The AERD subjects had worse lung functions and significantly longer asthma duration than the ATA subjects (Table 1). Medication use was different between the AERD and the ATA groups. No difference was found with respect to the ACT scores (Table 1).

\section{Asthma biomarkers}

Both AERD and ATA groups had significantly higher levels of uBrTyr, uLTE 4 , and blood eosinophils than $\mathrm{HC}$ (Fig. 1). Furthermore, $\mathrm{uLTE}_{4}$ levels and blood eosinophils were significantly higher in AERD as compared to ATA ( $p<0.0001, p=0.004$, respectively), whereas uBrTyr levels were not significantly different between these two asthmatic phenotypes ( $p=0.3406)$ (Fig. 1).

UBrTyr and $\mathrm{uLTE}_{4}$ levels correlated with each other both in the AERD $[R=0.160, p=0.01]$ and the ATA $[R=0.151, p=0.02]$ groups. Blood eosinophils correlated significantly with uLTE $_{4}$ levels in both asthma phenotypes [ATA: $R=0.165, \mathrm{p}=0.01$; AERD: $R=$ $0.276, \mathrm{p}<0.0001]$, whereas no such correlation was found with eosinophil counts and uBrTyr levels.

Both uBrTyr and uLTE $_{4}$ levels did not correlate with severity of airway obstruction measured by $\mathrm{FEV}_{1} \%$ predicted and $\mathrm{FEV}_{1} \% \mathrm{FVC}$ in either asthma phenotype, while only a borderline correlation was found between $\mathrm{FEV}_{1} \% \mathrm{FVC}$ and $\mathrm{uLTE}_{4}$ in ATA $[R=0.140, p=0.05]$.

To evaluate if studied biomarkers have the ability to predict an AERD diagnosis, values for each biomarker 
Table 1 Participant characteristics

\begin{tabular}{|c|c|c|c|c|c|}
\hline & $\operatorname{AERD}[n=240]$ & $\begin{array}{l}\text { ATA } \\
{[n=226]}\end{array}$ & $\begin{array}{l}\text { Control } \\
{[n=71]} \\
\end{array}$ & $\begin{array}{l}p \text {-value } \\
\text { (ANOVA) }\end{array}$ & T-Test \\
\hline \multicolumn{6}{|l|}{ Demographics } \\
\hline Age (yrs) & $49.3[0.8]$ & $49.7[1.0]$ & $44.3[1.6]$ & 0.008 & \\
\hline Gender $[\mathrm{M} / \mathrm{F}]$ & $74 / 166$ & $68 / 158$ & $35 / 36$ & 0.007 & \\
\hline BMI $\left(\mathrm{kg} / \mathrm{m}^{2}\right)$ & $26.7[0.3]$ & $27.1[0.4]$ & $25.6[1.0]$ & & \\
\hline Duration of asthma (yrs) & $18.8[0.8]$ & $15.2[1.0]$ & $\mathrm{n} / \mathrm{a}$ & & $<0.0001$ \\
\hline ACT; uncontrolled, n [\%] & $108[46]$ & $98[46]$ & $\mathrm{n} / \mathrm{a}$ & & \\
\hline \multicolumn{6}{|l|}{ Medication use } \\
\hline High dose ICS/Oral CS, n (\%) & $63(26)$ & $37(18)$ & $\mathrm{n} / \mathrm{a}$ & & 0.03 \\
\hline High dose ICS > $500(\mu \mathrm{g} / \mathrm{d}), \mathrm{n}(\%)$ & $62(26)$ & $52(25.5)$ & $\mathrm{n} / \mathrm{a}$ & & \\
\hline Low dose ICS $\leq 500$ ( $\mu \mathrm{g} / \mathrm{d}), \mathrm{n}(\%)$ & $78(33)$ & $92(44.7)$ & $\mathrm{n} / \mathrm{a}$ & & 0.008 \\
\hline No ICS or Oral CS, n (\%) & $3(14)$ & $25(12.4)$ & $\mathrm{n} / \mathrm{a}$ & & \\
\hline \multicolumn{6}{|l|}{ Lung functions } \\
\hline $\mathrm{FEV}_{1} \%$ predicted & $79.8[1.3]$ & $86.6[1.4]$ & $\mathrm{n} / \mathrm{a}$ & & 0.0003 \\
\hline $\mathrm{FEV}_{1} \% \mathrm{FVC}$ & $68.8[0.7]$ & $74.8[0.7]$ & $\mathrm{n} / \mathrm{a}$ & & $<0.0001$ \\
\hline
\end{tabular}

Mean (SEM); Definition of abbreviations: AERD Aspirin-Exacerbated Respiratory Disease, ATA Aspirin Tolerant Asthma, $M$ Male, $F$ Female, BMI Body mass index, FEV Forced expiratory volume in $1 \mathrm{~s}$, FVC Forced vital capacity, CS Corticosteroidsm, ICS Inhaled Corticosteroids

were dichotomized at cutoffs derived from ROC curve analyses. The cutoff value for uBrTyr was $0.101 \mathrm{ng} / \mathrm{mg}$ $\mathrm{Cr}$ (specificity $37 \%$, sensitivity $70 \%$ ), and the cutoff value for $\mathrm{uLTE}_{4}$ was $800 \mathrm{pg} / \mathrm{mg} \mathrm{Cr}$ (specificity $81 \%$, sensitivity $50 \%$ ). A high level of uBrTyr did not confer greater odds of having AERD (OR 1.3; 95\% Cl 0.9-2.0, $p=0.15$ ) (Fig. 2). The odds ratio for predicting AERD with respect to blood eosinophils > 300 cells/uL was 1.8 (95\% CI $1.2-$ 2.6, $p=0.003$ ) (Fig. 2). A high level of $\mathrm{uLTE}_{4}>800 \mathrm{pg} / \mathrm{mg}$ Cr conferred 4.1-fold odds of having AERD (95\% CI 2.7$6.3 ; p<0.0001)$. The combination of high blood eosinophils together with high $\mathrm{uLTE}_{4}$ levels increased the odds for AERD diagnosis 6.0-fold (95\% CI 3.4-10.9, $\mathrm{p}<0.0001$ ), with frequency of AERD of 79.6\% (74/93) among asthmatics with both characteristics versus 39.5\% (77/195) among patients with neither characteristic. Asthmatics with a combination of high blood eosinophil counts, $\mathrm{uLTE}_{4}$ levels, and uBrTyr levels had 7.1 times greater odds to have AERD than patients with none of the biomarkers elevated (95\% CI 3.4-15.8, p<0.0001) (Fig. 2), with frequency of AERD of $83.1 \%$ (59/71) among asthmatics with all three characteristics versus $41.0 \%(32 / 78)$ among patients with none of the characteristics. In the multivariable model with all 3 biomarkers, uBrTyr did not show
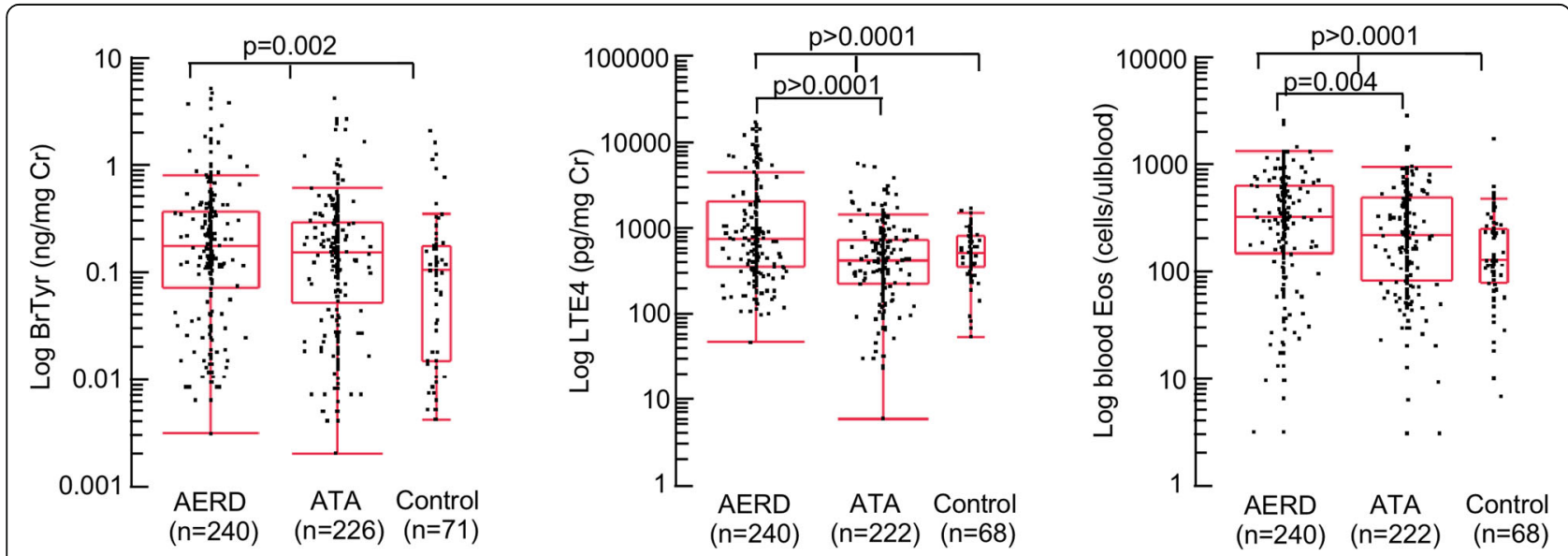

Fig. 1 Asthma biomarkers in AERD, ATA and control subjects. Evaluation of urinary BrTyr, urinary LTE 4 , and blood eosinophils in patients with Aspirin-Exacerbated Respiratory Disease (AERD) ( $n=240)$, patients with Aspirin-Tolerant Asthma (ATA) $(n=222)$, and control subjects ( $n=68)$. All markers were significantly different between the three groups (ANOVA, $p<0.05$ ). Urinary BrTyr was the only biomarker not significantly different between ATA and AERD $(p>0.05)$ 


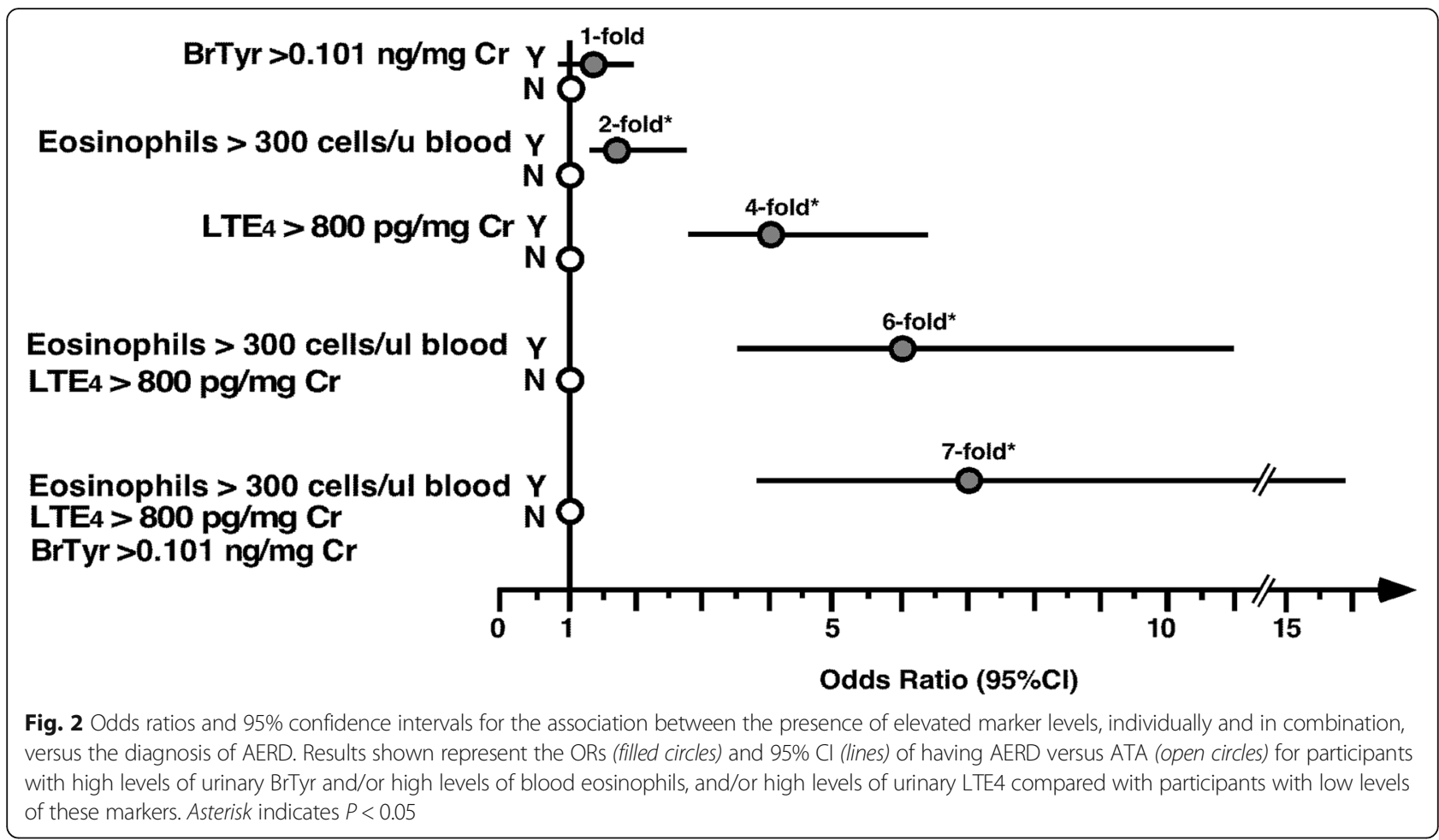

statistically significant evidence of an additive benefit for predicting AERD when uLTE $_{4}$ and blood eosinophils were already taken into account [adjusted odds ratio 1.1, 95\% CI 0.8-1.7, $p=0.57$ ].

When performing further covariate adjustment for baseline $\mathrm{FEV}_{1} \%$, chronic rhinosinusitis, and steroid use, the combination of high blood eosinophils together with high $\mathrm{uLTE}_{4}$ levels increased the odds for AERD diagnosis 3.5-fold (95\% CI 1.7-7.4, $p=0.0007$ ), which was smaller than the 6.0-fold estimate without the additional covariate adjustments. Asthmatics with a combination of high blood eosinophil counts, $\mathrm{uLTE}_{4}$ levels, and uBrTyr levels had covariate-adjusted 7.7 times greater odds to have AERD than patients with none of the biomarkers elevated (95\% CI 2.8-24.7, $p=0.0002)$, which was slightly higher than the 7.1-fold estimate obtained without the additional covariate adjustments. The additive benefit of uBrTyr for predicting AERD when $\mathrm{uLTE}_{4}$ and blood eosinophils were already taken into account also jumped upward a bit [adjusted odds ratio 1.5, 95\% CI $0.9-2.5, p=0.09]$ when adjusting for the additional covariates, compared to the 1.1 -fold increase estimated without the additional adjustments. The adjustment for steroid use was also performed with respect to only high dose steroid use, but the odds ratio estimates for the biomarkers was virtually identical to those obtained with the adjustment for any steroid use. Using ROC curves, 10-fold cross-validated AUC estimates were 0.82 for the full model and for models excluding either uBrTyr or blood eosinophils, while the exclusion of $\mathrm{uLTE}_{4}$ yielded an estimate of 0.79 . This is not surprising given that among the biomarkers, only $\mathrm{ULTE}_{4}$ levels yielded a statistically significant association with AERD when adjusting for the other biomarkers and the selected covariates.

The cutpoint for uBrTyr level to predict asthma regardless of phenotype was $>0.17 \mathrm{ng} / \mathrm{mg} \mathrm{Cr}$ (specificity, 79\%; sensitivity, 45\%). Subjects with baseline uBrTyr levels $>0.17 \mathrm{ng} / \mathrm{mg} \mathrm{Cr}$ were 3.1 times (95\% CI 1.7-5.8], $p>0.0002)$ as likely to have asthma.

\section{Discussion}

Aspirin challenge is currently considered as the gold standard and the only reliable method for the diagnosis of AERD. However, due to certain limitations of this procedure, an intensive search for in vitro diagnostic biomarkers useful in identifying patients with AERD is underway.

Novel biomarkers such as serum periostin [23], plasma eosinophil-derived neurotoxin [24], serum levels of $\mathrm{LTE}_{4}$, and $\mathrm{LTE}_{4} / \mathrm{PGF}_{2}$ alfa ratio [25] have been suggested but are not routinely done as in vitro diagnostic tests. They require verification in further studies.

As the imbalance of arachidonic acid metabolism and increased inflammation are important pathophysiologic features of AERD, we investigated if a panel of biomarkers reflecting these imbalances could be used for the prediction of this asthma phenotype. The current study confirmed previous reports that $\mathrm{uLTE}_{4}$ levels and 
blood eosinophil counts are increased in AERD patients as compared with ATA patients [9, 11, 26-28]. Additionally, it revealed that both elevated blood eosinophil count and increased $\mathrm{uLTE}_{4}$ levels separately enhanced the chance of AERD diagnosis 1.8-fold and 4.2-fold, respectively. The novel finding is that the combination of these two biomarkers powers that prediction 6.0-fold.

Recently, Bochenek et al. demonstrated that a set of clinical parameters comprising nasal polyps, upper airway symptoms, nasal corticosteroid treatment, asthma exacerbations, $\mathrm{FEV}_{1} \%$ predicted, and age of asthma onset had a superior accuracy in the prediction of AERD diagnosis to the measurement of $\mathrm{uLTE}_{4}$ level alone [11]. Addition of high uLTE $_{4}$ level to clinical parameters slightly enhanced the prediction of such diagnosis.

Ban et al. analyzed a metabolite profile that involved the arachidonic acid pathway for discriminating AERD from ATA and revealed that serum levels of $\mathrm{LTE}_{4}$ and even more so $\mathrm{LTE}_{4} / \mathrm{PGF}_{2} \alpha$ ratio can be potential in vitro diagnostic biomarkers for AERD [25]. Thus, similarly to the current study, the combination of two biomarkers together improved the diagnostic value of the test.

Eosinophils and mast cells play an important role in the pathogenesis of AERD [7]. Studies have suggested that eosinophils in AERD are driving cysteinyl leukotrienes overproduction and eosinophils proteins, e.g. ECP increased following aspirin provocation fast [29, 30]. Previous findings showed that uBrTyr can be used as (1) a molecular fingerprint of eosinophil activation; (2) a predictor of asthma and asthma exacerbation; and (3) a biomarker for asthma severity and corticosteroid responsiveness $[15,16,31-34]$. Despite serving as a marker for eosinophil activation, uBrTyr levels did not correlate with the amount of blood eosinophils found in either the AERD or in the ATA group. The study by Mita et al. on very small groups of patients with AERD $(n=12)$, ATA $(n=12)$, and control subjects $(n=18)$ showed also that higher uBrTyr levels in asthmatics were not related to the presence of aspirin sensitivity, but rather to their asthma alone [35]. As shown previously with asthmatic adult and pediatric populations [31, 32, 35], in our cohort of adult asthmatics uBrTyr levels were also increased in asthma when compared with $\mathrm{HC}$ and could be used as a biomarker of asthma. However, a higher uBrTyr level alone cannot distinguish patients with AERD from patients with ATA, and thus it cannot be used as a single parameter helpful in the diagnosis of AERD. The multivariable modeling conducted presently demonstrates a slight predictive benefit of uBrTyr level in addition to the use of elevated blood eosiniphils and elevated $\mathrm{uLTE}_{4}$ that is enhanced with covariate adjustment for $\mathrm{FEV}_{1} \%$, chronic rhinosinusitis, and steroid use, though not reaching a magnitude of statistical significance $(p=0.09)$.

\section{Conclusion}

This study reveals that uBrTyr levels are increased both in AERD and in ATA but cannot identify AERD. This suggested that the activation and the role of eosinophils in the controlled asthma is similar regardless aspirin hypersensitivity. The addition of uBrTyr to elevated uLTE4 levels and blood eosinophils did not statistically enhance the prediction of AERD diagnosis.14.

\section{Abbreviations}

AERD: Aspirin-exacerbated respiratory disease; ATA: Aspirin-tolerant asthma; COX: Cyclooxygenase; CysLTs: Cysteinyl leukotrienes; HC: Healthy controls; HPLC: High Performance Liquid Chromatography; LOX: Lipoxygenase; LTC4S: Leukotriene $\mathrm{C}_{4}$ synthase; UBrTyr: Urinary 3-bromotyrosine; ULTE U U $_{4}$ Urinary leukotriene $_{4} \mathrm{E}$

\section{Acknowledgements \\ Not applicable}

\section{Funding}

National Institutes of Health (HL103453, HL081064), the Alfred Lerner Memorial Chair in Innovative Biomedical Research. Mass spectrometry studies were performed on instruments housed in a facility partially supported by a Center of Innovation Award by AB SCIEX. Grant from the Jagiellonian University Medical College (K/ZDS/002794). "The funders had no role in study design, data collection and analysis, decision to publish, or preparation of the manuscript."

\section{Availability of data and materials}

Data and materials has not been made public in any online repository. Questionnaires and consent forms are stored locally as paper. Datasets are stored on a select few local computers.

\section{Authors' contributions \\ SAAC, SLH and SCE, literature search, data analysis/interpretation, figures, and writing; ENM, GB, study design, data collection /interpretation, figures, writing; TS and MS- study design, data collection, SBM and ZW- data collection; JPH, statistical analysis. All authors read and approved the final manuscript.}

Ethics approval and consent to participate

The Ethics Committee at Jagiellonian University approved the study, which was carried out according to the declaration of Helsinki. All participants provided written informed consent.

\section{Consent for publication}

Not applicable

\section{Competing interests}

$\mathrm{SLH}$ is named as co-inventor on pending and issued patents held by the Cleveland Clinic relating to cardiovascular diagnostics and asthmatic therapeutics, and has the right to receive royalty payment for inventions or discoveries both related tocardiovascular and asthmatic diagnostics or therapeutics from the Cleveland Clinic, Quest Diagnostics and Proctor \& Gamble. SLH also reports having been paid as a Consultant from Proctor \& Gamble, and having received research funds from Proctor \& Gamble and Roche.DD.

\section{Publisher's Note}

Springer Nature remains neutral with regard to jurisdictional claims in published maps and institutional affiliations.

\section{Author details}

${ }^{1}$ Cleveland Clinic, Lerner Research Institute, 9500 Euclid Avenue, NB2-40, Cleveland, OH 44195, USA. ${ }^{2}$ Department of Internal Medicine, Faculty of Medicine, Jagiellonian University Medical College, Krakow, Poland.

${ }^{3}$ Respiratory Institute, Cleveland Clinic, Cleveland, USA. 
Received: 25 April 2018 Accepted: 9 October 2018

Published online: 30 October 2018

\section{References}

1. Rajan JP, Wineinger NE, Stevenson DD, White AA. Prevalence of aspirinexacerbated respiratory disease among asthmatic patients: a meta-analysis of the literature. J Allergy Clin Immunol. 2015;135(3):676-81 e671.

2. Stevenson DD, Szczeklik A. Clinical and pathologic perspectives on aspirin sensitivity and asthma. J Allergy Clin Immunol. 2006;118(4):773-86 quiz 787-778,

3. Moon JY, Kim SH, Kim TB, et al. Aspirin-intolerant asthma in the Korean population: prevalence and characteristics based on a questionnaire survey. Respir Med. 2013;107(2):202-8.

4. Szczeklik A, Nizankowska E, Duplaga M. Natural history of aspirin-induced asthma. AIANE investigators. European network on aspirin-induced asthma. Eur Respir J. 2000;16(3):432-6.

5. Bochenek G, Szafraniec K, Kuschill-Dziurda J, Nizankowska-Mogilnicka E. Factors associated with asthma control in patients with aspirin-exacerbated respiratory disease. Respir Med. 2015;109(5):588-95.

6. Szczeklik A, Gryglewski RJ, Czerniawska-Mysik G. Relationship of inhibition of prostaglandin biosynthesis by analgesics to asthma attacks in aspirin-sensitive patients. Br Med J. 1975;1(5949):67-9.

7. Cowburn AS, Sladek K, Soja J, et al. Overexpression of leukotriene C4 synthase in bronchial biopsies from patients with aspirin-intolerant asthma. J Clin Invest. 1998:101(4):834-46.

8. Israel E, Fischer AR, Rosenberg MA, et al. The pivotal role of 5-lipoxygenase products in the reaction of aspirin-sensitive asthmatics to aspirin. Am Rev Respir Dis. 1993;148(6 Pt 1):1447-51

9. Kumlin M, Dahlen B, Bjorck T, Zetterstrom O, Granstrom E, Dahlen SE. Urinary excretion of leukotriene E4 and 11-dehydro-thromboxane B2 in response to bronchial provocations with allergen, aspirin, leukotriene D4, and histamine in asthmatics. Am Rev Respir Dis. 1992;146(1):96-103.

10. Divekar R, Hagan J, Rank M, et al. Diagnostic utility of urinary LTE4 in asthma, allergic rhinitis, chronic rhinosinusitis, nasal polyps, and aspirin sensitivity. J Allergy Clin Immunol Pract. 2016:4(4):665-70.

11. Bochenek G, Stachura T, Szafraniec K, et al. Diagnostic accuracy of urinary LTE4 measurement to predict aspirin-exacerbated respiratory disease in patients with asthma. J Allergy Clin Immunol Pract. 2018;6(2):528-35. https://doi.org/10.1016/j.jaip.2017.07.001.

12. Laidlaw TM, Kidder MS, Bhattacharyya N, et al. Cysteinyl leukotriene overproduction in aspirin-exacerbated respiratory disease is driven by platelet-adherent leukocytes. Blood. 2012;119(16):3790-8.

13. Bousquet J, Chanez P, Lacoste JY, et al. Eosinophilic inflammation in asthma. N Engl J Med. 1990;323(15):1033-9.

14. Wenzel SE. Asthma phenotypes: the evolution from clinical to molecular approaches. Nat Med. 2012;18(5):716-25.

15. MacPherson JC, Comhair SA, Erzurum SC, et al. Eosinophils are a major source of nitric oxide-derived oxidants in severe asthma: characterization of pathways available to eosinophils for generating reactive nitrogen species. J Immunol. 2001:166(9):5763-72.

16. Wu W, Samoszuk MK, Comhair SA, et al. Eosinophils generate brominating oxidants in allergen-induced asthma. J Clin Invest. 2000;105(10):1455-63.

17. Nizankowska-Mogilnicka E, Bochenek G, Mastalerz L, et al. EAACI/GA2LEN guideline: aspirin provocation tests for diagnosis of aspirin hypersensitivity. Allergy. 2007;62(10):1111-8

18. Macy E, Bernstein JA, Castells MC, et al. Aspirin challenge and desensitization for aspirin-exacerbated respiratory disease: a practice paper. Ann Allergy Asthma Immunol. 2007;98(2):172-4.

19. National Asthma Education and Prevention Programme. Expert Panel Report 3: guidelines for the diagnosis and management of asthma. https:// www.nhlbi.nih.gov/health-pro/guidelines/current/asthma-guidelines2007.

20. Nathan RA, Sorkness CA, Kosinski M, et al. Development of the asthma control test: a survey for assessing asthma control. J Allergy Clin Immunol. 2004;113(1):59-65.

21. Katz LE, Gleich GJ, Hartley BF, Yancey SW, Ortega HG. Blood eosinophil count is a useful biomarker to identify patients with severe eosinophilic asthma. Ann Am Thorac Soc. 2014;11(4):531-6.

22. Price DB, Rigazio A, Campbell JD, et al. Blood eosinophil count and prospective annual asthma disease burden: a UK cohort study. Lancet Respir Med. 2015; 3(11):849-58.
23. Kim MA, Izuhara K, Ohta S, et al. Association of serum periostin with aspirinexacerbated respiratory disease. Ann Allergy Asthma Immunol. 2014;113(3): 314-20.

24. Shin SW, Park JS, Park CS. Elevation of eosinophil-derived neurotoxin in plasma of the subjects with aspirin-exacerbated respiratory disease: a possible peripheral blood protein biomarker. PLoS One. 2013;8(6):e66644.

25. Ban GY, Cho K, Kim SH, et al. Metabolomic analysis identifies potential diagnostic biomarkers for aspirin-exacerbated respiratory disease. Clin Exp Allergy. 2017:47(1):37-47.

26. Christie PE, Tagari P, Ford-Hutchinson AW, et al. Urinary leukotriene E4 concentrations increase after aspirin challenge in aspirin-sensitive asthmatic subjects. Am Rev Respir Dis. 1991;143(5 Pt 1):1025-9.

27. Smith CM, Hawksworth RJ, Thien FC, Christie PE, Lee TH. Urinary leukotriene E4 in bronchial asthma. Eur Respir J. 1992;5(6):693-9.

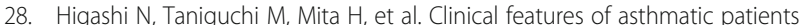
with increased urinary leukotriene E4 excretion (hyperleukotrienuria): involvement of chronic hyperplastic rhinosinusitis with nasal polyposis. J Allergy Clin Immunol. 2004;113(2):277-83.

29. Choi GS, Kim JH, Shin YS, Ye YM, Kim SH, Park HS. Eosinophil activation and novel mediators in the aspirin-induced nasal response in AERD. Clin Exp Allergy. 2013:43(7):730-40.

30. Steinke JW, Payne SC, Borish L. Eosinophils and mast cells in aspirinexacerbated respiratory disease. Immunol Allergy Clin N Am. 2016;36(4): 719-34

31. Wedes $\mathrm{SH}$, Khatri SB, Zhang $\mathrm{R}$, et al. Noninvasive markers of airway inflammation in asthma. Clin Transl Sci. 2009;2(2):112-7.

32. Wedes SH, Wu W, Comhair SA, et al. Urinary bromotyrosine measures asthma control and predicts asthma exacerbations in children. J Pediatr. 2011;159(2):248-55 e241.

33. Wu W, Chen Y, d'Avignon A, Hazen SL. 3-Bromotyrosine and 3,5dibromotyrosine are major products of protein oxidation by eosinophil peroxidase: potential markers for eosinophil-dependent tissue injury in vivo. Biochemistry. 1999:38(12):3538-48.

34. Wu W, Chen Y, Hazen SL. Eosinophil peroxidase nitrates protein tyrosyl residues. Implications for oxidative damage by nitrating intermediates in eosinophilic inflammatory disorders. J Biol Chem. 1999;274(36):25933-44.

35. Mita H, Higashi $N$, Taniguchi M, Higashi A, Kawagishi Y, Akiyama K. Urinary 3-bromotyrosine and 3-chlorotyrosine concentrations in asthmatic patients: lack of increase in 3-bromotyrosine concentration in urine and plasma proteins in aspirin-induced asthma after intravenous aspirin challenge. Clin Exp Allergy. 2004;34(6):931-8.

Ready to submit your research? Choose BMC and benefit from:

- fast, convenient online submission

- thorough peer review by experienced researchers in your field

- rapid publication on acceptance

- support for research data, including large and complex data types

- gold Open Access which fosters wider collaboration and increased citations

- maximum visibility for your research: over $100 \mathrm{M}$ website views per year

At $\mathrm{BMC}$, research is always in progress.

Learn more biomedcentral.com/submission 